\title{
Promotion of CO Oxidization and Inhibition of NO Formation by Gaseous Iron Species during High-Temperature Off-Gas Combustion
}

\author{
Sen Li and Xiaolin Wei \\ Institute of Mechanics, Chinese Academy of Sciences, No. 15 Beisihuanxi Road, Beijing, China, 100190
}

ABSTRACT: The promotion of CO oxidization and inhibition of NO formation by gaseous iron species were analyzed using the Sandia SENKIN program. It is shown that the relative ratio of $\mathrm{CO}$ oxidization dramatically varies with combustion time at early burning stage in the presence of iron species, and all peak values are greater than 2.4 . The relative ratio of $\mathrm{CO}$ oxidization decreases with the increase of air stoichiometric ratio and $\mathrm{CO}$ concentration in off-gas. The circulation reactions of $\mathrm{Fe}-\mathrm{FeO} / \mathrm{FeO}-\mathrm{Fe}$ achieve the catalytic effect on $\mathrm{CO}$ oxidization. Gaseous iron species can greatly inhibit NO formation, NO reduction ratio can reach above $70 \%$ at $T=2073$ and $2273 \mathrm{~K}$, and gaseous iron species can effectively inhibit NO formation when combustion temperature is not higher than $2273 \mathrm{~K}$ during the off-gas combustion. There are $\mathrm{O}_{2}$ competitive reactions between thermal $\mathrm{NO}$ formation and Fe oxidization, and high chemical activity of iron species inhibits thermal-NO formation.

\section{INTRODUCTION}

A large amount of high-temperature off-gas is produced during oxygen converter steelmaking, the major compositions of off-gas are $\mathrm{CO}$ and $\mathrm{CO}_{2}, \mathrm{CO}$ concentration varies from 15 to $70 \%$, and off-gas temperature can reach $1900 \mathrm{~K} .{ }^{1}$ In the meantime, off-gas entrains a large amount of fine dusts $\left(\mathrm{Fe}, \mathrm{FeO}, \mathrm{Fe}_{2} \mathrm{O}_{3}\right.$, etc. $)$ and the amount of the dusts entrained by off-gas is about $80-150 \mathrm{~g} / \mathrm{m}^{3.2}$.

The high-temperature off-gas is a precious valuable fuel. It is often discharged into the cooling stack to be combusted, and the peak temperature of flame can reach above $2000{ }^{\circ} \mathrm{C}$ where $\mathrm{CO}_{2}$ may decompose and $\mathrm{NO}_{x}$ is significantly formed. ${ }^{3} \mathrm{CO}$ emission concentration can reach above $2000 \mathrm{mg} / \mathrm{m}^{3}$ which is always over emission standards $\left(300 \mathrm{mg} / \mathrm{m}^{3}\right.$ in China). ${ }^{4,5} \mathrm{CO}$ is a toxic gas which is dangerous to human health. High $\mathrm{CO}$ emission results in not only atmospheric pollutant but also fuel loss. $\mathrm{NO}_{x}$ is a known precursor to the formation of ozone and acid rain, and it can react with volatile organic compounds to form photochemical smog. ${ }^{6}$

Iron oxide catalyst is widely used either as single metal oxide or as a mixed oxide in industrial processes, and iron oxide exhibits intermediate activity in the complete oxidation of methane and carbon monoxide. $^{7-9} \mathrm{NO}$ reduction by iron species has been studied in fluidized bed, and the results indicate that iron or its oxides cause a chemical reduction of $\mathrm{NO}$ in the presence of CO. ${ }^{10}$ It has been discovered that injection of iron-containing compounds into the combustion and reburning zones of conventional gas- and coal-fired combustors can increase the efficiency of $\mathrm{NO}_{x}$ reduction by up to $20 \%$ in comparison with that which can be achieved by basic reburning. ${ }^{11}$

During the combustion of high-temperature off-gas entraining a large amount of dust containing iron and iron oxides, gaseous iron species is present at $T>2073 \mathrm{~K}$, and it has effects on $\mathrm{CO}$ oxidization and $\mathrm{NO}$ formation. A detailed chemical kinetic mechanism for gaseous iron-species inhibition of flames, iron pentacarbonyl $\left(\mathrm{Fe}(\mathrm{CO})_{5}\right)$ mechanism, has been introduced, ${ }^{12}$ and modeling with the mechanism supports the premise that the inhibition is primarily a gas-phase phenomena. Many researchers used the $\mathrm{Fe}(\mathrm{CO})_{5}$ mechanism to investigate the influence of $\mathrm{Fe}(\mathrm{CO})_{5}$ on combustion flames, and the mechanism was validated by experimental results. ${ }^{12-16}$ Understanding the behaviors of promotion of $\mathrm{CO}$ oxidization and inhibition of $\mathrm{NO}$ formation by gaseous iron and iron oxides at high-temperature off-gas combustion is important for the control of $\mathrm{CO}$ and $\mathrm{NO}$ emissions. There are no reports in the literature of $\mathrm{NO}$ by ironcontaining compounds in steelmaking off-gas combustion conditions. The goal of this work is to gain better understanding of the mechanisms of the promotion of $\mathrm{CO}$ oxidization and inhibition of NO formation by gaseous iron species. In the paper, the combustion of off-gas in the presence of gaseous iron species was simulated using the Sandia SENKIN program, and the promotion of $\mathrm{CO}$ oxidization and inhibition of $\mathrm{NO}$ formation by gaseous iron species were analyzed.

\section{KINETIC MODEL}

The chemical kinetic behavior of reactants was modeled with the Sandia SENKIN program of CHEMKIN subroutines. ${ }^{17,18}$ The program solves the conservation equations for mass and energy. It can calculate the temporal evolution of mole fractions of species for a homogeneous mixture in a closed reactor and it can account for finite-rate elementary chemical reactions and perform kinetic sensitivity analysis. Therefore, the SENKIN model is appropriate to investigate the mechanisms of $\mathrm{CO}$ oxidization and $\mathrm{NO}$ reduction by gaseous iron species in the process of high-temperature off-gas combustion in a closed chamber. The reaction pathway flux analysis is performed using MixMaster (a Python program that is part of the Cantera suite), which is based on a conserved scalar approach to reaction fluxes. $^{19}$

The chemical kinetic model of off-gas combustion is from Linteris et al. ${ }^{20}$ In the mechanism, the $\mathrm{CO} / \mathrm{H}_{2} / \mathrm{O}_{2}$ system is from

Received: November 17, 2010

Revised: January 3, 2011

Published: February 02, 2011 


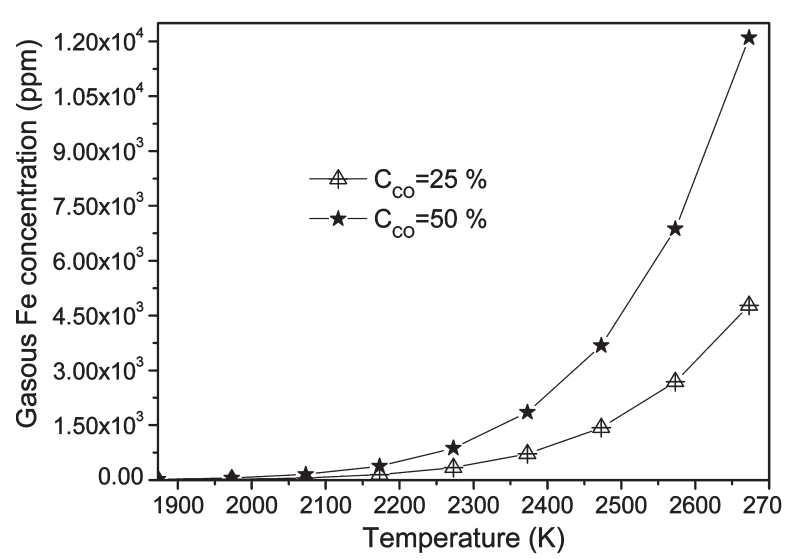

(a) $\mathrm{Fe}$

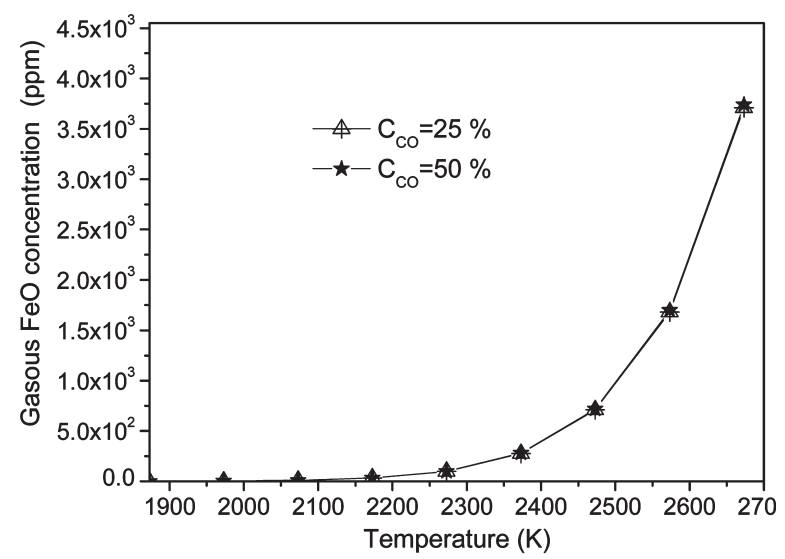

(b) $\mathrm{FeO}$

Figure 1. Initial concentration of gaseous iron species in high-temperature off-gas.

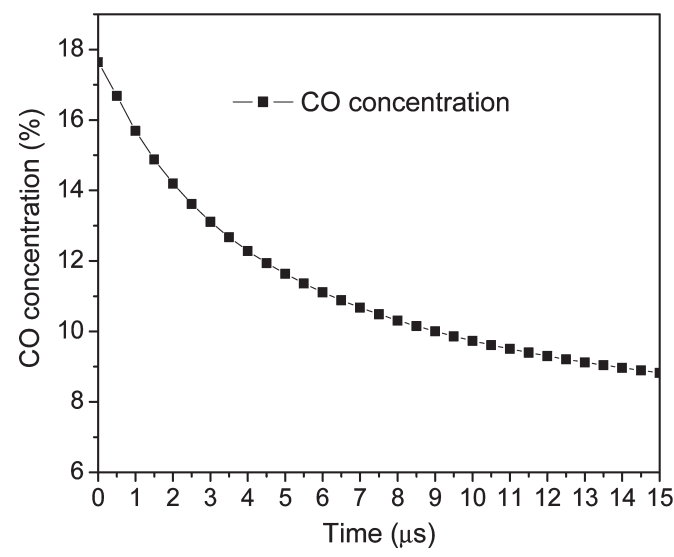

(a) in the absence of gaseous iron species

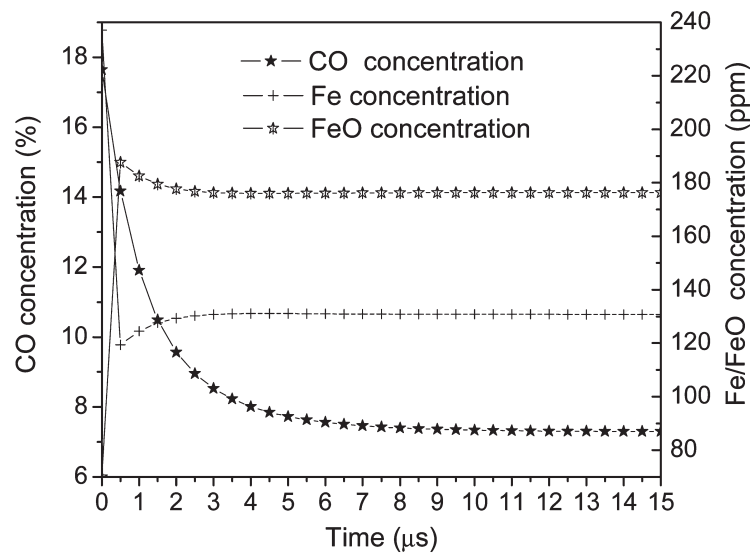

(b) in the presence of gaseous iron species

Figure 2. Concentrations of $\mathrm{CO}$, gaseous $\mathrm{Fe}$, and $\mathrm{FeO}$ during off-gas combustion at the initial $C_{\mathrm{CO}}=25 \%$, $\mathrm{SR}=0.7$, and $T=2273 \mathrm{~K}$.

Allen and Yetter, ${ }^{21}$ based upon that from Kim et al., ${ }^{22}$ while the gaseous iron species mechanism is from Rumminger et al. ${ }^{23}$ The $\mathrm{CO} / \mathrm{H}_{2} / \mathrm{O}_{2}$ submechanism has been extensively validated by experimental data in ref 22 , and the iron submechanism has been validated using flame speed data and diffusion flame extinction data. ${ }^{16,23-25}$

\section{SIMULATION CONDITIONS}

In the combustion simulation of high-temperature off-gas containing gaseous iron species by Sandia SENKIN model with the mechanism from Linteris, it is a case for an adiabatic constant pressure system $(P=1.01 \mathrm{bar})$. The initial compositions of offgas are $\mathrm{CO}$ and $\mathrm{CO}_{2}$, and the oxidizer is air. In the paper, $\mathrm{C}_{\mathrm{CO}}$ is the initial $\mathrm{CO}$ concentration in off-gas, and $\mathrm{C}_{\mathrm{CO}, 0}$ is the initial $\mathrm{CO}$ concentration in the gas mixture of off-gas and air during combustion. The promotion of $\mathrm{CO}$ oxidization and inhibition of $\mathrm{NO}$ formation by gaseous iron species are investigated at $\mathrm{C}_{\mathrm{CO}}$ $=25 \%$ and $50 \%$.

According to the analysis data of dust sampled at the cooling stack outlet $\left(72.0 \% \mathrm{Fe}_{2} \mathrm{O}_{3}, 0.80 \% \mathrm{SiO}_{2}\right.$, and $9.04 \% \mathrm{CaO}, 120 \mathrm{~g} /$ $\left.\mathrm{m}^{3}\right)_{2}^{2}$ using chemical equilibrium calculation by HSC chemistry $7.0,{ }^{26}$ the initial concentrations of gaseous iron species in hightemperature off-gas were calculated, as shown in Figure 1. Because the high-temperature off-gas originates from the high-temperature steel-smelting bath during converter steelmaking process, it can be considered that the gaseous $\mathrm{Fe}$ species is in an equilibrium saturated state in the high-temperature off-gas, thus the initial concentration of gaseous iron species calculated by chemical equilibrium is reasonable. The results of chemical equilibrium calculation indicate that the gaseous compositions of iron-containing species are $\mathrm{Fe}$ and $\mathrm{FeO}$; the concentrations of gaseous $\mathrm{Fe}$ and $\mathrm{FeO}$ increase with the increase of temperature; with the increase of $\mathrm{CO}$ concentration, the concentration of gaseous $\mathrm{Fe}$ increases, but $\mathrm{FeO}$ concentration is not effected.

Moisture content of air supplied for combustion is $0.6 \mathrm{wt} \%$. Air stoichiometric ratio (SR) represents the fuel-air mixture composition:

$\mathrm{SR}=($ actual air supplied $) /($ stoichiometric air demand of fuel $)$

In the paper, the influences of SR on $\mathrm{CO}$ oxidization and $\mathrm{NO}$ formation are investigated, and SR ranges from 0.3 to 1.2.

\section{RESULTS AND DISCUSSION}

4.1. Catalytic Effect of Gaseous Iron Species on CO Oxidization. Figure 2 compares the variations of $\mathrm{CO}$ concentrations during off-gas combustion in the presence and absence of gaseous 


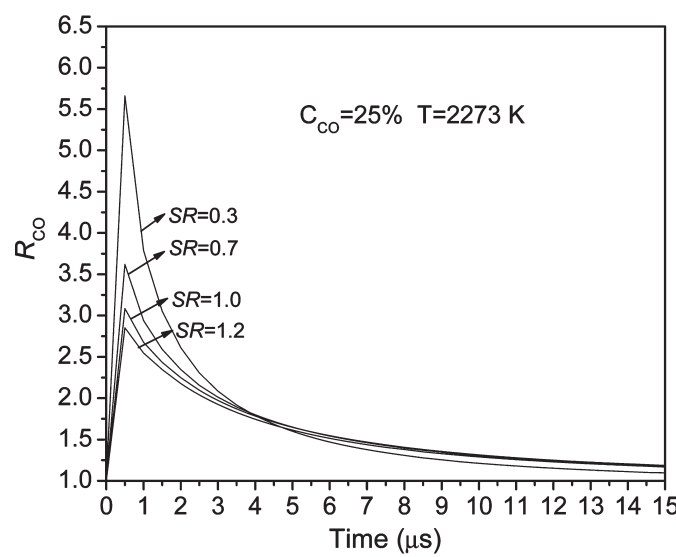

(a)

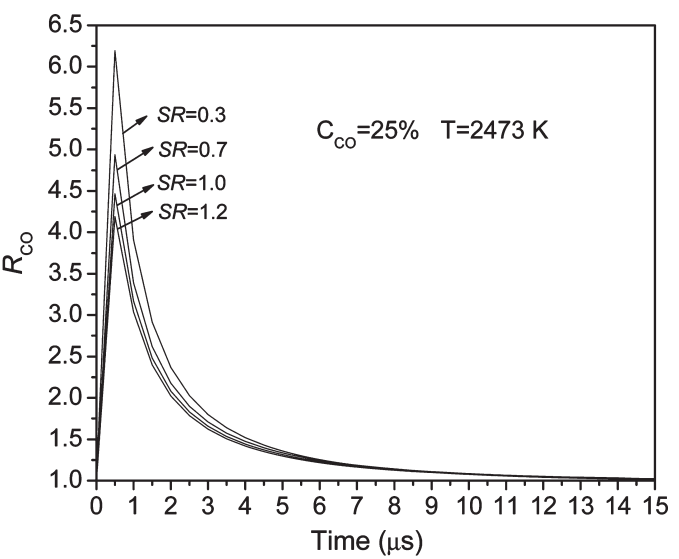

(b)

Figure 3. Influence of $\mathrm{SR}$ on the relative ratio of $\mathrm{CO}$ oxidization at $C_{\mathrm{CO}}=25 \%$.

iron species at $C_{\mathrm{CO}}=25 \%, \mathrm{SR}=0.7$ and $\mathrm{T}=2273 \mathrm{~K}$, and the concentrations of gaseous iron species are also provided in the presence of gaseous iron species during off-gas combustion. $\mathrm{CO}$ concentration in the presence of gaseous iron species decreases faster than that in the absence of gaseous iron species, indicating that gaseous iron species during off-gas can greatly promote $\mathrm{CO}$ oxidization.

To estimate the contribution of gaseous iron species to $\mathrm{CO}$ oxidization, the relative ratio of $\mathrm{CO}$ oxidization is defined as $\left(R_{\mathrm{CO}}\right)$

$$
R_{\mathrm{co}}=\frac{C_{\mathrm{CO}, 0}-C_{\mathrm{CO}, 2}}{C_{\mathrm{CO}, 0}-C_{\mathrm{CO}, 1}}
$$

where $C_{\mathrm{CO}, 0}$ is the initial $\mathrm{CO}$ concentration in the gas mixture of off-gas and air during off-gas combustion; $C_{\mathrm{CO}, 1}$ is the $\mathrm{CO}$ concentration in the absence of gaseous iron species during offgas combustion; $C_{\mathrm{CO}, 2}$ is the $\mathrm{CO}$ concentration in the presence of gaseous iron species during off-gas combustion. $R_{\mathrm{CO}}>1$ means that the presence of gaseous iron species during off-gas combustion is conducive to $\mathrm{CO}$ oxidization, and the higher $R_{\mathrm{CO}}$, the more significant the catalytic effect of gaseous iron species on $\mathrm{CO}$ oxidization.

In Figure 3, the relative ratio of $\mathrm{CO}$ oxidization is shown as a function of time at $C_{\mathrm{CO}}=25 \%$ and $\mathrm{SR}=0.3-1.2$. The simulation results indicate the following: at early burning stage $(t<3 \mu \mathrm{s})$, $R_{\mathrm{CO}}$ dramatically varies with combustion time, it has a peak value when combustion time is $0.5 \mu \mathrm{s}$ or so, all of the peak values of $R_{\mathrm{CO}}$ are greater than 2.7, and increasing SR makes $R_{\mathrm{CO}}$ decrease; at $t>5 \mu \mathrm{s}, R_{\mathrm{CO}}$ moderately decreases with combustion time and tends to 1 , and SR has little effect on $R_{\mathrm{CO}} ; R_{\mathrm{CO}}$ at $T=2473 \mathrm{~K}$ is higher than that at $T=2273 \mathrm{~K}$.

In Figure 4, the relative ratio of $\mathrm{CO}$ oxidization is shown at initial $C_{\mathrm{CO}}=50 \%$ and $\mathrm{SR}=0.3-1.2$. When comparing $R_{\mathrm{CO}}$ at $\mathrm{CO}_{\mathrm{CO}, 0}=25 \%$ and $50 \%$ (see Figures 3 and 4), increasing $C_{\mathrm{CO}}$ makes $R_{\text {co }}$ decrease.

To understand the influence mechanism of gaseous iron species on $\mathrm{CO}$ oxidization, the normalized sensitivity of $\mathrm{CO}$ concentration toward reactions is calculated. The sensitivity analysis coefficients are obtained through perturbation of the pre-exponential factor $A$ in the Arrhenius equation of reactions, and the normalized sensitivity coefficient $\left(S_{j}\right)$ is defined as

$$
S_{i}=\frac{\partial \ln c}{\partial \ln k_{i}}
$$

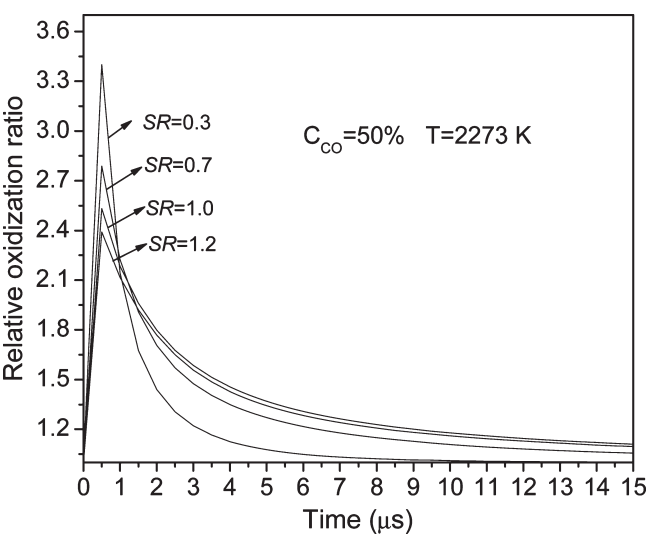

Figure 4. Influence of $\mathrm{SR}$ on relative $\mathrm{CO}$ oxidization ratio at $\mathrm{C}_{\mathrm{CO}}=$ $50 \%$.

where $c$ is $\mathrm{CO}$ concentration, and $k_{i}$ is the pre-exponential factor $A$ in the Arrhenius equation of the reaction $i$. The value of the sensitivity coefficient indicates a positive or negative influence on $c$ by $k_{i}$, a positive value means that the value of $c$ increases as $k_{i}$ increases and a negative value means that the value of $c$ decreases as $k_{i}$ increases. The reason for the high value of this coefficient is that the reaction is the key chain branching step and strongly promotes $\mathrm{CO}$ oxidation.

As known from Figure 5, the normalized sensitivity coefficients of reactions R1R1-R4R4 are the top 4, meaning the four reactions are most important for $\mathrm{CO}$ oxidization. All of the reactions R1R1-R4R4 involve gaseous iron species, and these reactions comprise the catalytic $\mathrm{CO}$ oxidization.

$$
\begin{gathered}
\mathrm{Fe}+\mathrm{O}_{2}=\mathrm{FeO}+\mathrm{O} \\
\mathrm{FeO}_{2}+\mathrm{O}=\mathrm{FeO}+\mathrm{O}_{2} \\
\mathrm{FeO}+\mathrm{CO}=\mathrm{Fe}+\mathrm{CO}_{2} \\
\mathrm{Fe}+\mathrm{O}_{2}=\mathrm{FeO}_{2} \\
\text { Net reaction } \mathrm{O}_{2}+2 \mathrm{CO}=2 \mathrm{CO}_{2}
\end{gathered}
$$

Therefore, during the combustion of high-temperature off-gas, gaseous iron species have great catalytic effect on $\mathrm{CO}$ oxidization. 
The peak values of the sensitivity coefficient of reactions $\mathrm{R} 1 \mathrm{R} 1-\mathrm{R} 4 \mathrm{R} 4$ coincide in time at the early stage of off-gas combustion. These reactions are responsible for the rapid increase of the relative ratio of $\mathrm{CO}$ oxidization at early burning stage in Figures 3 and 4, indicating that gaseous containing-iron species during off-gas can greatly promote CO oxidization.

The primary reaction pathways for $\mathrm{CO}$ and iron species are shown in Figure 6. Figure 6a indicates that the most important reaction of $\mathrm{CO}$ oxidization in the absence of iron species is

$$
\mathrm{OH}+\mathrm{CO}=\mathrm{H}+\mathrm{CO}_{2}
$$

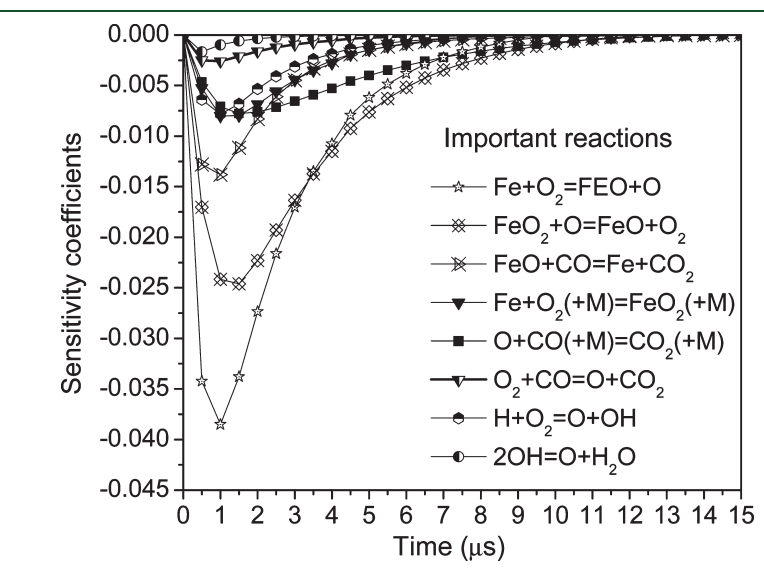

Figure 5. Sensitivity of $\mathrm{CO}$ concentrations toward the most important reactions at $C_{\mathrm{CO}}=25 \%, T=2273 \mathrm{~K}$, and $\mathrm{SR}=0.7$.
$\mathrm{OH}$ is crucial to $\mathrm{CO}$ oxidization. $\mathrm{OH}$ radical is formed to accelerate $\mathrm{CO}$ oxidation in the presence of even a small quantity of hydrogen-containing material. ${ }^{27}$ For off-gas combustion, offgas contains virtually no hydrogen-containing material, $\mathrm{OH}$ only originates from $\mathrm{H}_{2} \mathrm{O}$ vapor supplied by combustion air stream, and $\mathrm{OH}$ is principally obtained by the following mechanisms:

$$
\begin{gathered}
\mathrm{H}_{2} \mathrm{O}+\mathrm{O} \rightarrow 2 \mathrm{OH} \\
\mathrm{H}_{2} \mathrm{O}+\mathrm{H} \rightarrow \mathrm{OH}+\mathrm{H}_{2}
\end{gathered}
$$

Therefore, during off-gas combustion, $\mathrm{H}_{2} \mathrm{O}$ vapor supplied by combustion air stream is very important, and the absence of $\mathrm{H}_{2} \mathrm{O}$ may make the oxidation of $\mathrm{CO}$ extremely slow.

Figure $6 \mathrm{~b}$ illustrates the reaction pathways for $\mathrm{CO}$ oxidization in the presence of gaseous iron species. It indicates that there are three reaction pathways of $\mathrm{CO}$ oxidization: (1) $\mathrm{FeO}+\mathrm{CO}=\mathrm{Fe}$ $+\mathrm{CO}_{2}$; (2) $\mathrm{OH}+\mathrm{CO}=\mathrm{H}+\mathrm{CO}_{2}$; (3) $\mathrm{O}+\mathrm{CO}=\mathrm{CO}_{2}$. The first reaction pathway is the most important pathway and accounts for $72 \%$ contribution for $\mathrm{CO}$ oxidization. Here, a portion of $\mathrm{Fe}$ is converted first to $\mathrm{FeO}_{2}$ and then to $\mathrm{FeO}$, the remainder of the $\mathrm{Fe}$ is directly converted to $\mathrm{FeO}$, and $\mathrm{FeO}$ participates in $\mathrm{CO}$ oxidization to be reduced into $\mathrm{Fe}$. In the series of reactions, and the circulation reactions of $\mathrm{Fe}-\mathrm{FeO} / \mathrm{FeO}_{2}-\mathrm{Fe}$ achieve the catalytic effect on $\mathrm{CO}$ oxidization, which predominates $\mathrm{CO}$ oxidization. The secondary pathway of $\mathrm{CO}$ oxidation is the same as that in the absence of iron species mentioned in Figure 6a; it accounts for $26 \%$ contribution for CO oxidization in the presence of iron species which accounts for $84 \%$ in the absence of iron species, and the pathway originates from the reaction of $\mathrm{CO}$ and $\mathrm{H}_{2} \mathrm{O}$ vapor supplied by combustion air

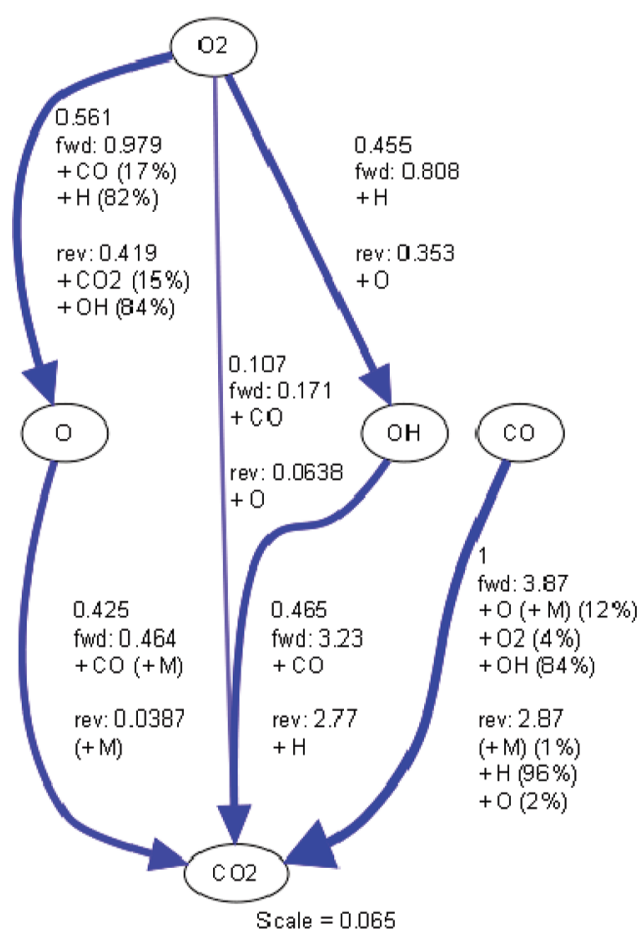

(a) in the absence of iron species

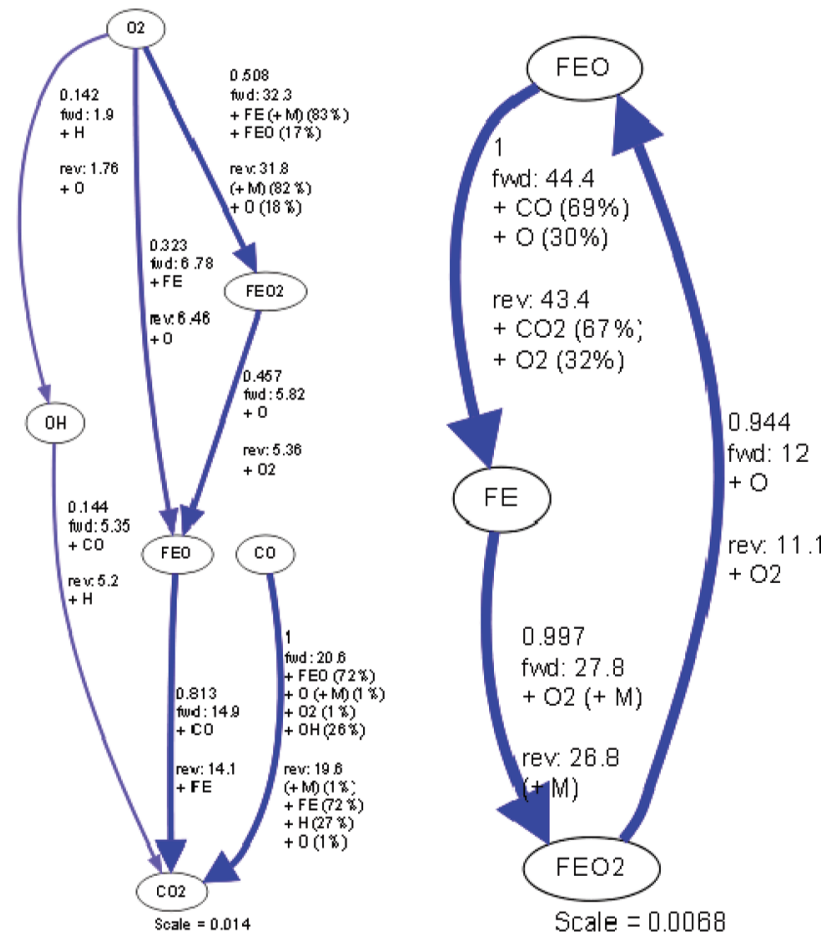

(b) in the presence of iron species

Figure 6. Schematic diagram of reaction pathways for $\mathrm{CO}$ and iron species at $C_{\mathrm{CO}}=25 \%$ in off-gas, $T=2273 \mathrm{~K}, \mathrm{SR}=0.7$, and $t=1 \mu \mathrm{s}$. The percentages presented in some paths represent the contribution of that path to the consequent species. Large arrows represent the important paths for both consumed and produced species. 
stream. The third reaction pathway $\mathrm{CO}$ oxidation accounts for only $1 \%$ contribution for CO oxidization, and it is negligible.

Based on the above analysis of sensitivity and reaction pathways, the influences of $S R$, temperature, and $C_{\mathrm{CO}}$ on the relative ratio of $\mathrm{CO}$ oxidization are discussed. Figures 3 and 4 indicate that increasing SR makes the relative ratio of $\mathrm{CO}$ oxidization decrease at the early combustion stage. To investigate the reason, the schematic diagrams of reaction pathways for $\mathrm{CO}$ oxidization

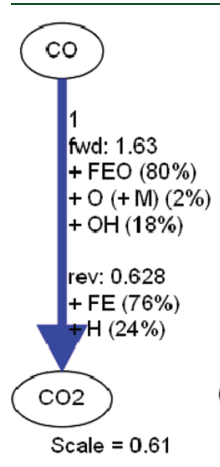

(a) $\mathrm{SR}=0.3$

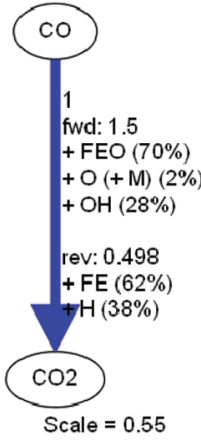

(b) $\mathrm{SR}=0.7$

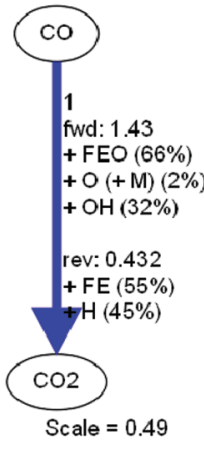

(c) $\mathrm{SR}=1.0$

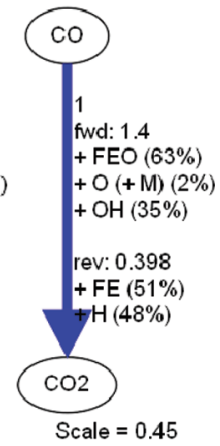

(c) $\mathrm{SR}=1.2$
Figure 7. Schematic diagrams of reaction pathways for $\mathrm{CO}$ oxidization at $C_{\mathrm{CO}}=25 \%$ in off-gas, $T=2273 \mathrm{~K}$, and $t=1 \mu \mathrm{s}$.

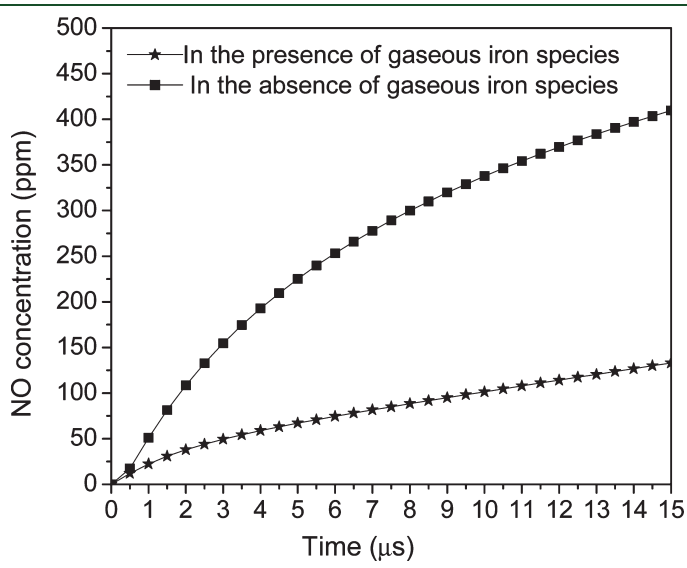

Figure 8. NO concentration during off-gas combustion in the presence and absence of gaseous containing-iron species at initial $C_{\mathrm{CO}}=25 \%$ in off-gas, $\mathrm{SR}=0.7$, and $T=2273 \mathrm{~K}$. at different SR are presented in Figures 7. The results indicate that, with the increase of $\mathrm{SR}$, the contribution rate of $\mathrm{R} 3(\mathrm{FeO}+$ $\left.\mathrm{CO}=\mathrm{Fe}+\mathrm{CO}_{2}\right)$ for $\mathrm{CO}$ oxidization decreases, but the contribution rate of $\mathrm{R} 5\left(\mathrm{OH}+\mathrm{CO}=\mathrm{H}+\mathrm{CO}_{2}\right)$ for $\mathrm{CO}$ oxidization increases. When SR increases from 0.3 to 1.2 , the increasing air supplied dilutes the concentration of gaseous iron species in the gas mixture of off-gas and air, the initial concentration Fe species decreases from 285 to $196 \mathrm{ppm}$, but the initial concentration $\mathrm{H}_{2} \mathrm{O}$ vapor supplied by air stream increases from 48 to $133 \mathrm{ppm}$. Since the reaction rate of $\mathrm{R} 3$ is larger that of $\mathrm{R} 5$, the decrease of the initial concentration Fe species with $\mathrm{SR}$ is not conducive to $\mathrm{CO}$ oxidization. The catalytic effect of gaseous iron species on $\mathrm{CO}$ oxidization reduces, thus the relative ratio of $\mathrm{CO}$ oxidization deceases with the increase of SR at early stage of off-gas combustion (see Figures 3 and 4). In Figure 3, the reason for the increase of the relative ratio of $\mathrm{CO}$ oxidization with the increase of temperature is as follows: the reaction rate coefficients have exponential relationship with combustion temperature, increasing temperature strengthens catalytic effect of gaseous iron species on $\mathrm{CO}$ oxidization, and then the relative ratio of $\mathrm{CO}$ oxidization at $T=2473 \mathrm{~K}$ is higher than that at $T=2273 \mathrm{~K}$ (see Figure 3). In Figures 3 and 4, the reason for the decrease of the relative ratio of $\mathrm{CO}$ oxidization with the increase of $C_{\mathrm{CO}}$ is as follows: the off-gas combustion with high-concentration $\mathrm{CO}$ needs more air provided, and a large amount of combustion air results in the decrease of the concentration of gaseous iron species, the catalytic effect of gaseous iron species on $\mathrm{CO}$ oxidization is weakened, and then the relative $\mathrm{CO}$ ratio of oxidization deceases at early stage of off-gas combustion with the decrease of $C_{\mathrm{CO}}$ as compared between Figure 3 and Figure 4.

4.2. Catalytic Effect of Gaseous Iron Species on NO Formation. Figure 8 compares the variations of NO concentration during off-gas combustion in the presence and absence of gaseous iron species at $C_{\mathrm{CO}}=25 \%, \mathrm{SR}=0.7$ and $T=2273 \mathrm{~K}$. $\mathrm{NO}$ concentration in the presence of gaseous iron species is much lower than that in the absence of gaseous iron species, indicating that gaseous iron species can greatly inhibit NO formation.

To estimate the effect of gaseous iron species on NO formation, $\mathrm{NO}$ reduction ratio is defined as $R_{\mathrm{NO}}$

$$
R_{\mathrm{NO}}=\frac{C_{\mathrm{NO}, 2}-C_{\mathrm{NO}, 1}}{C_{\mathrm{NO}, 2}} \times 100 \%
$$

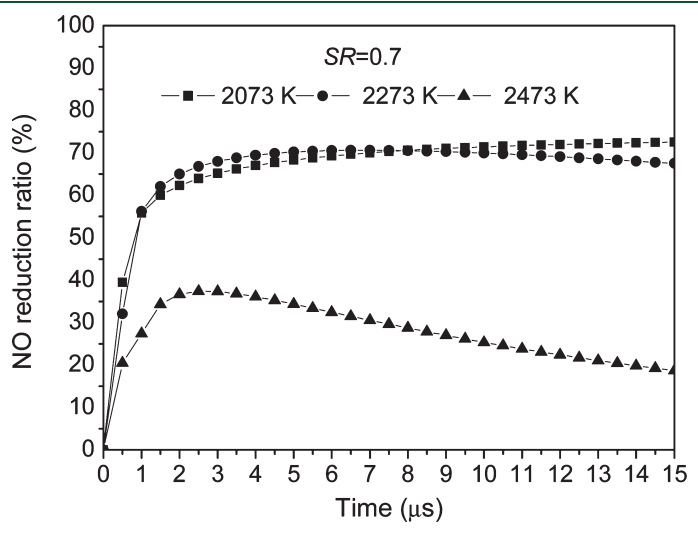

(a)

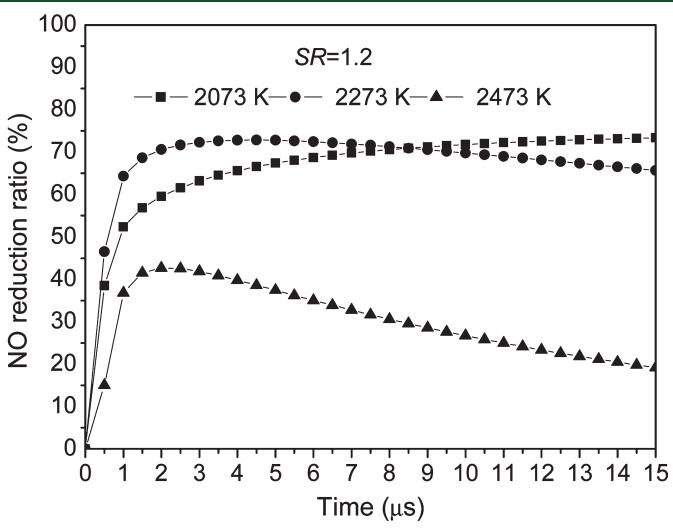

(b)

Figure 9. Influence of temperature and SR on relative $\mathrm{CO}$ oxidization ratio at $\mathrm{C}_{\mathrm{CO}}=25 \%$. 


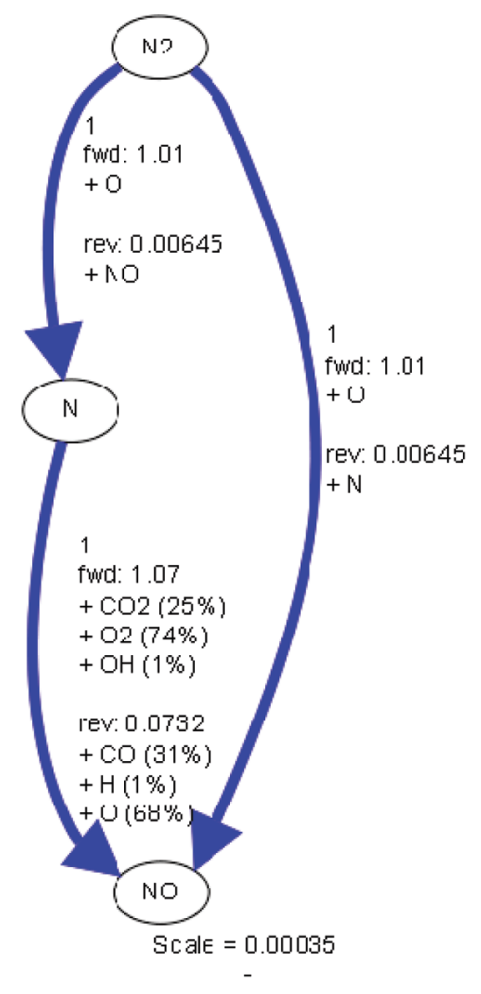

(a) in the absence of iron species

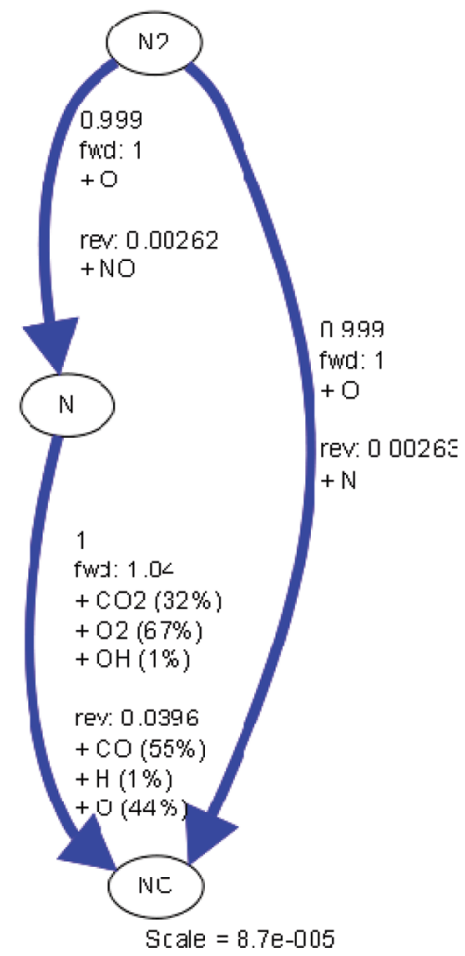

(b) in the presence of iron species

Figure 10. Schematic diagram of reaction pathways for $\mathrm{NO}$ formation at $C_{\mathrm{CO}}=25 \%, T=2273 \mathrm{~K}, \mathrm{SR}=1.2$, and $t=1 \mu \mathrm{s}$. The percentages presented in some paths represent the contribution of that path to the consequent species. Large arrows represent the important paths for both consumed and produced species.

where $C_{\mathrm{NO}, 1}$ is the $\mathrm{NO}$ concentration in the presence of gaseous iron species, and $C_{\mathrm{NO}, 2}$ is the $\mathrm{NO}$ concentration in the absence of gaseous iron species.

Figure 9 shows NO reduction ratio of off-gas in the presence of gaseous iron species at $\mathrm{SR}=0.7$ and 1.2. $\mathrm{NO}$ reduction ratio can reach above $70 \%$ at $T=2073$ and $2273 \mathrm{~K}$, but it is less than $50 \%$ at $T=2473 \mathrm{~K}$. NO reduction ratio slightly increases with the increase of SR. The results indicate that gaseous iron species can effectively inhibit $\mathrm{NO}$ formation when combustion temperature is not higher than $2273 \mathrm{~K}$ during the off-gas combustion.

Figure.10 shows NO formation pathways during the off-gas combustion in the absence and presence of gaseous iron species, and the results indicate that major reaction pathways of $\mathrm{NO}$ formation in the absence and presence of gaseous iron are similar, where $\mathrm{N}_{2} / \mathrm{N}$ mainly reacts with $\mathrm{O}_{2}$ and $\mathrm{O}$ to form $\mathrm{NO}$.

To understand $\mathrm{NO}$ formation mechanism, by using the rate of production (ROP) analyses, NO production rates of reactions were calculated (see Figure 11). The top three reactions during high-temperature off-gas combustion in the absence and presence of gaseous iron are the same, and they are following reactions:

$$
\begin{gathered}
\mathrm{N}_{2}+\mathrm{O}=\mathrm{N}+\mathrm{NO} \\
\mathrm{N}+\mathrm{O}_{2}=\mathrm{NO}+\mathrm{O} \\
\mathrm{N}+\mathrm{CO}_{2}=\mathrm{NO}+\mathrm{CO}
\end{gathered}
$$

Reactions R8R8 and R9R9 are thermal-NO or Zeldovich$\mathrm{NO}$; thermal-NO is produced from the reaction of nitrogen and oxygen gases in the air during combustion, especially at high temperatures. Reaction R8R8 has a very high activation energy due to the strong trip bond in the $\mathrm{N}_{2}$-molecule, and is thus sufficient at high-temperature. The formation of thermal-NO is determined by a set of highly temperature-dependent chemical reactions known as the extended Zeldovich mechanism.

The presence of $\mathrm{CO}_{2}$ has a significant effect on $\mathrm{NO}$ formation by reaction $\mathrm{R} 10 \mathrm{R} 10$, the high concentration of $\mathrm{CO}_{2}$ makes more $\mathrm{NO}$ formation. At initial stage of off-gas combustion, NO production rates of the reactions R8R8 and R9R9 rapidly increase because of high $\mathrm{O}_{2}$ concentration, and then the production rates decreases with combustion time because of the decrease of $\mathrm{O}_{2}$ concentration (see Figure 11).

As compared with the NO production rates during off-gas in the absence of gaseous iron, the NO production rates are noticeably low in the presence of gaseous iron, indicating that gaseous iron species plays a key role in the NO reduction. To investigate the reasons for the inhibition mechanism of NO formation by gaseous iron species, the normalized sensitivity of NO concentration toward reactions involving gaseous iron species reactions is calculated, and the top three sensitivities of $\mathrm{NO}$ concentration toward reactions involving gaseous iron reactions are shown in Figure 12.

The sensitivity analysis reflects the relative importance of different reactions with respect to the NO mole fraction. Figure 11 indicates that the reactions of iron species greatly influence NO formation, and the top three reactions are the 


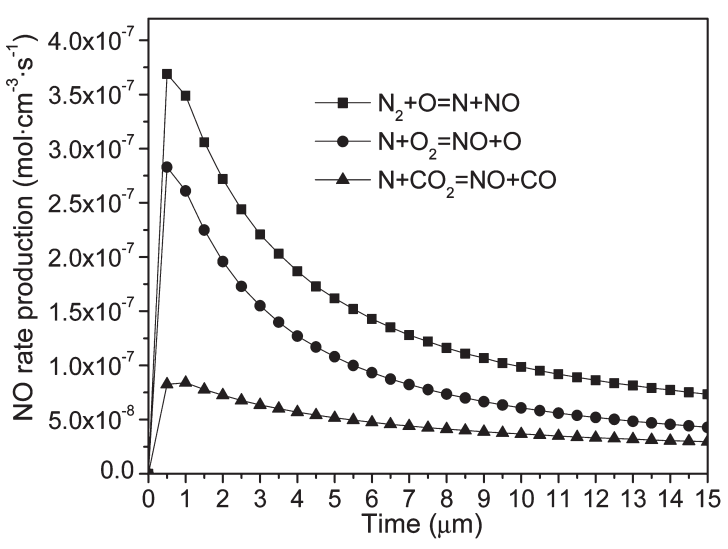

(a) in the absence of gaseous iron species

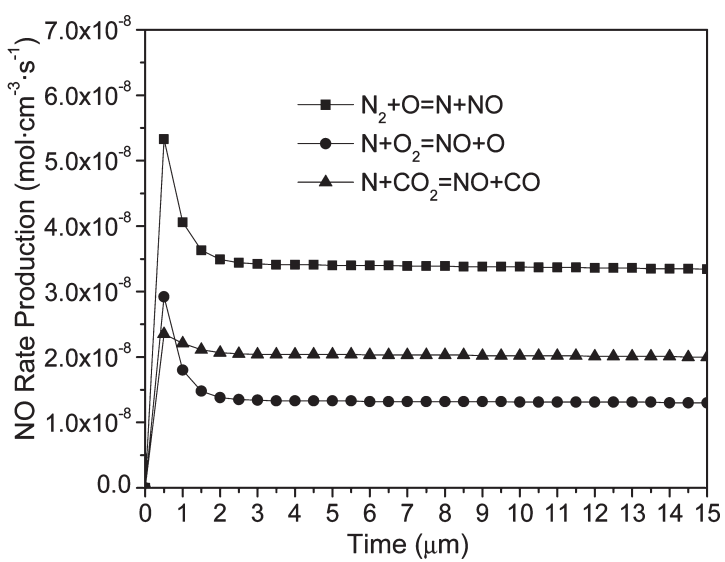

(b) in the presence of gaseous iron species

Figure 11. Rate of production (ROP) analyses of $\mathrm{NO}$ formation at $C_{\mathrm{CO}}=25 \%, T=2273 \mathrm{~K}$, and $\mathrm{SR}=1.2$.

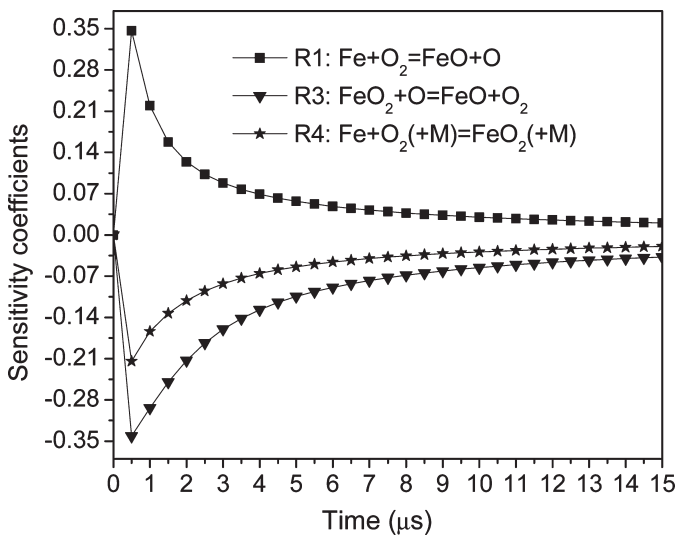

Figure 12. Sensitivity of NO concentrations toward the most important reactions at $T=2273 \mathrm{~K}, \mathrm{SR}=1.2$, and $C_{\mathrm{CO}}=25 \%$.

following:

$$
\begin{gathered}
\mathrm{Fe}+\mathrm{O}_{2}=\mathrm{FeO}+\mathrm{O} \\
\mathrm{Fe}+\mathrm{O}_{2}=\mathrm{FeO}_{2} \\
\mathrm{FeO}_{2}+\mathrm{O}=\mathrm{FeO}+\mathrm{O}_{2}
\end{gathered}
$$

Net reaction $: 2 \mathrm{Fe}+\mathrm{O}_{2}=2 \mathrm{FeO}$

Reactions R1R1, R3R3, and R4R4 play a key role not only in $\mathrm{CO}$ oxidization but also in $\mathrm{NO}$ formation. $\mathrm{O}_{2}$ is very important for thermal-NO formation. As mentioned above, reactions R1R1-R4R4 have the catalytic effect of $\mathrm{CO}$ oxidization, and they play a role of $\mathrm{O}_{2}$ transfer for $\mathrm{CO}$ oxidization. The circulation reactions of $\mathrm{Fe}-\mathrm{FeO} / \mathrm{FeO}_{2}-\mathrm{Fe}$ predominate $\mathrm{CO}$ oxidization, but thermal $\mathrm{NO}$ greatly depends on $\mathrm{O}_{2}$. Thus, there are $\mathrm{O}_{2}$ competitive reactions between thermal $\mathrm{NO}$ formation and $\mathrm{Fe}$ oxidization. High chemical activity of iron species easily reacts with $\mathrm{O}_{2} / \mathrm{O}$ (see Figure $6 \mathrm{~b}$ ), thus thermal-NO formation is inhibited. In short, the gaseous iron species promotes $\mathrm{CO}$ oxidation and inhibits NO formation in the combustion of off-gas.

\section{CONCLUSION}

In the paper, a numerical simulation of the promotion of $\mathrm{CO}$ oxidization and inhibition of $\mathrm{NO}$ formation by gaseous iron species during the combustion of converter steelmaking off-gas was performed using the Sandia SENKIN program of CHEMKIN subroutines. In the presence of iron species, at early burning stage $(t<3 \mu \mathrm{s}), R_{\mathrm{CO}}$ dramatically varies with combustion time, all of the peak values of $R_{\mathrm{CO}}$ are greater than 2.4 , and increasing SR makes $R_{\mathrm{CO}}$ decrease. These reactions comprise the catalytic $\mathrm{CO}$ oxidization: $\mathrm{Fe}+\mathrm{O}_{2}=\mathrm{FeO}+\mathrm{O}, \mathrm{FeO}_{2}+\mathrm{O}=\mathrm{FeO}+\mathrm{O}_{2}, \mathrm{Fe}+$ $\mathrm{O}_{2}=\mathrm{FeO}_{2}, \mathrm{FeO}+\mathrm{CO}=\mathrm{Fe}+\mathrm{CO}_{2}$. The circulation reactions of $\mathrm{Fe}-\mathrm{FeO} / \mathrm{FeO}_{2}-\mathrm{Fe}$ achieve the catalytic effect on $\mathrm{CO}$ oxidization. Gaseous iron species can greatly inhibit $\mathrm{NO}$ formation, and NO reduction ratio can reach above $70 \%$ at $T=2073$ and $2273 \mathrm{~K}$. Gaseous iron species can effectively inhibit NO formation when combustion temperature is not higher than $2273 \mathrm{~K}$ during the off-gas combustion. There are $\mathrm{O}_{2}$ competitive reactions between thermal NO formation and Fe oxidization, and high chemical activity of iron species inhibits thermal-NO formation.

\section{AUTHOR INFORMATION}

\section{Corresponding Author}

Telephone: +8610-82544231. Fax: +86 10 82544231. E-mail: lisen@imechac.cn.

\section{ACKNOWLEDGMENT}

Financial support by National Natural Science Foundation of China (50976123) and the Knowledge Innovation Program of the Chinese Academy of Sciences (KGCX2-YW-321) is acknowledged.

\section{NOMENCLATURE}

$C_{\mathrm{CO}}=$ initial $\mathrm{CO}$ concentration in off-gas (\%)

$C_{\mathrm{CO}, 0}=$ initial $\mathrm{CO}$ concentration in the gas mixture of off-gas and air during combustion (\%)

$C_{\mathrm{CO}, 1}=\mathrm{CO}$ concentration in the absence of gaseous iron species during off-gas combustion (\%)

$C_{\mathrm{CO}, 2}=\mathrm{CO}$ concentration in the presence of gaseous iron species during off-gas combustion

$T=$ combustion temperature $(\mathrm{K})$

$\mathrm{SR}=$ air stoichiometric ratio

$R_{\mathrm{CO}}=$ the relative ratio of $\mathrm{CO}$ oxidization

$R_{\mathrm{NO}}=\mathrm{NO}$ reduction ratio $(\%)$

$S_{j}=$ the normalized sensitivity coefficient 


\section{REFERENCES}

(1) Li, S. Study on the formation, flow, and reaction process of metallurgical furnace off-gas/flue gas. Chinese Academy of Sciences Post-Doctoral Work Report, 2010.

(2) Feng, J. H. Steelmaking Design Principles; Chemical Industry Press: Beijing, 2005.

(3) Li, S.; Wei, X. L.; Yu, L. X. Appl. Energy 2011, 88, 1113-9.

(4) Bada, H.; Yamada, S.; Yaji, M.; Kodaka, S. F. M. Improvement in off-gas recovery from Q-BOP. Kwasaki Steel Technical Report, 1983.

(5) Emission standards for iron and steel industry (DB37/ 990-2008). http://www.sdein.gov.cn/art/ 2008/5/15/art_39_128545. html.

(6) Li, S.; Xu, T. M.; Sun, P.; Zhou, Q. L.; Tan, H. Z. Fuel 2008, 87, 723-31.

(7) Kwon, S. C.; Fan, M.; Wheelock, T. D.; Sahab, B. Sep. Purif. Technol. 2007, 58, 40-48.

(8) Reddy, B. V.; Rasouli, F.; Hajaligol, M. R.; Khanna, S. N. Fuel 2004, 83, 1537-41.

(9) Kalinkin, A. V.; Savchenko, V. I.; Pashis, A. V. Catal. Lett. 1999, 59, 115-9.

(10) Hayhurst, A. N.; Lawrence, A. D. Combust. Flame 1997, 110, 351-65.

(11) Lissianski, V. V.; Maly, P. M.; Zamansky, V. M. Ind. Eng. Chem. Res. 2001, 40, 3287-93.

(12) Rumminger, M. D.; Reinelt, D.; Babushok, V.; Linteris, G. T. Combust. Flame 1999, 116, 207-19.

(13) Vladimir, M.; Shvartsberg; Tatyana, A. B.; Oleg, P. K. Energy Fuels 2010, 24, 1552-8.

(14) Staude, S.; Atakan, B. Open Thermodyn. J. 2009, 3, 42-6.

(15) Linteris, G. T.; Rumminger, M. D.; Babushok, V. Premixed Carbon Monoxide-Nitrous Oxide-Hydrogen Flames: Measured and Calculated Burning Velocities with and without $\mathrm{Fe}(\mathrm{CO})_{5}$; NISTIR 6374; National Institute of Standards and Technology: Gaithersburg, MD, 1999.

(16) Rummingera, M. D.; Linteris, G. T. Combust. Flame 2000, 120, 451-64.

(17) SENKIN: A Fortran Program for Predicting Homogeneous Gas Phase Cehmical Kinetics With Sensitivity Analysis; SAND87-8248; Sandia National Laboratories: Livermore, CA, 1988.

(18) CHEMKIN-II: A Fortran Chemical Kinetics Package for the Analysis of Gas Phase Chemical Kinetics; SAND89-8009B; Sandia National Laboratories: Livermore, CA, 1989.

(19) Object-Oriented Software for Reacting Flows. http://www. cantera.org.

(20) Linteris, G. T.; Babushok, V. I. Proc. Combust. Inst. 2009, 32, $2535-42$.

(21) Allen, M. T.; Yetter, R. A.; Dryer, F. L. Combust. Flame 1997, 109, 449-470.

(22) Kim, T. J.; Yetter, R. A.; Dryer, F. L. Proc. Combust. Inst. 1994, 25, 759-66.

(23) Rumminger, M. D.; Babushok, D. V. I.; Linteris, G.T.. Combust. Flame 1999, 116, 207-19.

(24) Linteris, G. T.; Rumminger, M. D.; Babushok, V. I. Combust. Flame 2000, 122, 58-75.

(25) Rumminger, M. D.; Linteris, G. T. Fire Safety Science: Proc. of the Sixth Int. Symp; Int. Assoc. for Fire Safety Science: Marne-La-Vallee, France, 2000; pp 289-300.

(26) Outotec Solutions website. www.outotec.com/hsc.

(27) Law, C. K. Combustion Physics; Cambridge University Press: Cambridge, U.K., 2006. 